Article

\title{
Three Novel Zn-Based Coordination Polymers: Synthesis, Structure, and Effective Detection of $\mathrm{Al}^{3+}$ and $S^{2-}$ Ions
}

\author{
Yuna Wang ${ }^{1,2,+}$, Xiaofeng Zhang ${ }^{1,2,+}$, Yanru Zhao ${ }^{1,2}$, Suoshu Zhang ${ }^{1,2}$, Shifen Li ${ }^{1,2}$, Lei Jia ${ }^{1,2}$, \\ Lin $\mathrm{Du}^{1,2, *}$ and Qihua Zhao ${ }^{1,2, *}$ \\ 1 School of Chemical Science and Technology Pharmacy, Yunnan University, Kunming 650091, China; \\ wyn123456LL@163.com (Y.W.); zxf123456LL@163.com (X.Z.); zyr123456LL@163.com (Y.Z.); \\ zss123456@163.com (S.Z.); 1sf123456LL@163.com (S.L.); j1123456LLL@163.com (L.J.) \\ 2 Key Laboratory of Medicinal Chemistry for Natural Resource Education Ministry, Yunnan University, \\ Kunming 650091, China \\ * $\quad$ Correspondence: lindu@ynu.edu.cn (L.D.); qhzhao@ynu.edu.cn (Q.Z.); Tel.: +86-871-6503-5640 (L.D.) \\ + These authors contributed equally to this work.
}

Received: 27 December 2019; Accepted: 12 January 2020; Published: 17 January 2020

\begin{abstract}
Three novel Zn-based coordination polymers (CPs), [Zn(MIPA) $]_{n}(\mathbf{1}),\left\{\left[\mathrm{Zn}(\mathrm{MIPA})\left(4,4^{\prime}-\right.\right.\right.$ bipy $\left.\left.)_{0.5}\left(\mathrm{H}_{2} \mathrm{O}\right)\right] \cdot 1.5 \mathrm{H}_{2} \mathrm{O}\right\}_{\mathrm{n}}(2)$, and $\left\{[\mathrm{Zn}(\mathrm{MIPA})(\mathrm{bpe})] \cdot \mathrm{H}_{2} \mathrm{O}\right\}_{\mathrm{n}}$ (3) (MIPA = 4-methoxyisophthalic acid, 4, $4^{\prime}$-bipy $=4,4^{\prime}$-bipyridine, bpe $=(\mathrm{E})-1,2$-di(pyridine-4-yl)ethane), were constructed by ligand 4-methoxyisophthalic acid under solvothermal conditions. Compound $\mathbf{1}$ features a beaded 2D-layer architecture, while compound 2 presents a 2 -fold interpenetrating structure with a uninodal three-connected hcb topology. Compound $\mathbf{3}$ has a 3-fold interpenetrated four-connected $\mathbf{d m p}$ topology. Photoluminescence investigations of compound $\mathbf{2}$ were explored in detail, by which ions were detected, and it was observed to have the highest quenching efficiency toward $\mathrm{Al}^{3+}$ and $\mathrm{S}^{2-}$ ions. The possible fluorescence quenching mechanisms of 2 toward $\mathrm{Al}^{3+}$ and $\mathrm{S}^{2-}$ ions were also explored. To the best of our knowledge, this is the first potential dual-responsive luminescent probe based on a $\mathrm{Zn}(\mathrm{II})$ coordination polymer for detecting $\mathrm{Al}^{3+}$ and $\mathrm{S}^{2-}$ ions via a luminescence quenching effect in ethanol.
\end{abstract}

Keywords: coordination polymers; 4-methoxyisophthalic acid; ion detection; ethanol

\section{Introduction}

As interest in environmental and health concepts grows, the effects of various ions on the biological environment and human health are popular focus points. Aluminum and sulfur ions play an important part in our daily lives and are not able to be substituted due to their peculiarly superior properties, such as the light weight and corrosion resistance of the metal aluminum, and the participation of sulfur ions in physiological processes [1,2]. However, if the aluminum ion or sulfur ion content in the body is high, it will affect human health. The concentration of aluminum ions accumulated in the human body can result in metabolic disorders. Abnormal production of sulfur ions is associated with many diseases, including loss of consciousness and respiratory paralysis [3,4]. In addition, sulfur ions are important pollutants in the environment and are widely found in various polluted water sources. Therefore, it is very important to urgently establish a rapid and effective analytical method for the determination of aluminum and sulfur ions or to find a substance that has a specific and sensitive ability to recognize them.

Coordination polymers (CPs) have aroused much interest, owing to their potential applications in catalysis [5-7], adsorption [8,9], separation [10], electrochemistry [11-13], and as chemical 
sensors [14-17]. In recent years, coordination polymers (CPs) used as fluorescent sensors have been successfully applied in the determination of various analytes such as metal ions $\left(\mathrm{Fe}^{3+}, \mathrm{Cr}_{2} \mathrm{O}_{4}{ }^{2-}\right.$, etc.) [18-20], small molecules (acetylacetone, water, etc.) [21,22], and explosives (TNT, PA, etc.) [23-25]. Coordination polymers have become one of the hotspots of material chemistry as new fluorescent probes because of their high sensitivity and selectivity, ease of operation, convenience, and fast response time [26-29]. There has been evidence that $\mathrm{Zn}$-based coordination polymers present prominent superiority, especially in the field of fluorescence sensing [30,31]. He et al. designed a Zn-based multi-responsive luminescent probe with a discriminatory ability for $\mathrm{Fe}^{3+}, \mathrm{Al}^{3+}, \mathrm{SiF}_{6}{ }^{2-}, \mathrm{Cr}_{2} \mathrm{O}_{7}{ }^{2-}$, nitrofurantoin (NFT), and nitrofurazone (NFZ) via the change of luminescence intensity [32]. The $\mathrm{Zn}$ (II) ion, as a $\mathrm{d}^{10}$ metal ion, can greatly enhance the rigidity and fluorescent yield of coordination polymers [33,34]. Furthermore, Zn-based CPs are able to display the ligand-centered characteristic emission. As such, Zn-based CPs used as fluorescent sensors usually change the fluorescence properties by means of the incorporation, functionalization, and modification of the ligands [35,36]. Therefore, it is fascinating and significant to design and synthesize luminescent materials using $\mathrm{Zn}$ (II) ions and the control of ligands.

Herein, we reported three novel Zn-based coordination polymers: $[\mathrm{Zn}(\mathrm{MIPA})]_{\mathrm{n}}(\mathbf{1}),\left\{\left[\mathrm{Zn}(\mathrm{MIPA})\left(4,4^{\prime}-\right.\right.\right.$ bipy) $\left.\left.0_{0.5}\left(\mathrm{H}_{2} \mathrm{O}\right)\right] \cdot 1.5 \mathrm{H}_{2} \mathrm{O}\right\}_{n}(2)$, and $\left\{[\mathrm{Zn}(\mathrm{MIPA})(\mathrm{bpe})] \cdot \mathrm{H}_{2} \mathrm{O}\right\}_{\mathrm{n}}(3)$ (MIPA = 4-methoxyisophthalic acid, bpe $=(\mathrm{E})-1,2$-di(pyridine-4-yl)ethane), which were constructed by introducing an $\mathrm{N}$-donor ligand and controlling solvents. The solid fluorescence properties of compounds 1-3 were investigated, and results clearly indicated that compound 2 has a good fluorescence performance in $\mathrm{Al}^{3+}$ and $\mathrm{S}^{2-}$ detection, with high selectivity and sensitivity. As far as we know, this is the first $\mathrm{Zn}$-based coordination polymer which can be used as a dual functional fluorescent material to detect $\mathrm{Al}^{3+}$ and $\mathrm{S}^{2-}$ ions by means of luminescence quenching in ethanol.

\section{Results}

\subsection{Crystal Structure of $[\mathrm{Zn}(\mathrm{MIPA})]_{n}(\mathbf{1})$}

Single crystal X-ray analysis showed that compound 1 crystallizes in the orthorhombic Pbca space group, presenting a 2D multi-metallic linear cluster structure. The asymmetrical unit consists of one $\mathrm{Zn}$ (II) ion and one MIPA ligand. Each hexacoordinated $\mathrm{Zn}$ (II) center with a $\mathrm{ZnO}_{6}$ binding set displays a distorted octahedral geometry, created by five carboxylic $\mathrm{O}$ atoms from four different MIPA ligands (Zn-O: 1.958(4), 1.997(4), 2.008(4), 2.016(4) ̊) and one methoxy O atom (Zn-O: 2.482(4) ̊) (Figure 1a). The MIPA ligand is completely deprotonated with the coordination mode of $\mu_{4}-\mathrm{K}^{5} \mathrm{O}^{\prime}, \mathrm{O}^{\prime \prime}, \mathrm{O}^{\prime \prime \prime}, \mathrm{O}^{\prime \prime \prime \prime}: \mathrm{O}^{\prime \prime \prime \prime \prime \prime}$. (Scheme 1, mode I). Two carboxyl groups from different MIPA ligands are used to bridge the neighboring $\mathrm{Zn}$ (II) ions into 1D multi-metallic ( $\mathrm{Zn}-\mathrm{O})_{\mathrm{n}}$ chains ( $\mathrm{Zn} \cdots \mathrm{Zn}$ distance is $3.519 \AA$ ) , and the neighboring 1D multi-metallic chains are further connected into a beaded 2D-layer structure by MIPA ligands (Figure $1 \mathrm{~b}, \mathrm{c}$ ). The 2D-layer structure is further assembled into a 3D supermolecule frame by $\pi \cdots \pi$ interaction between layers (Figure 1d).

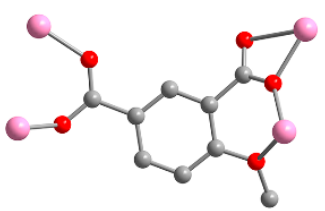

mode I

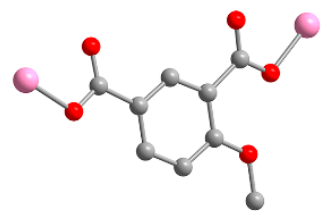

mode II

Scheme 1. Coordination modes of an MIPA (4-methoxyisophthalic acid) ligand. 
(a)

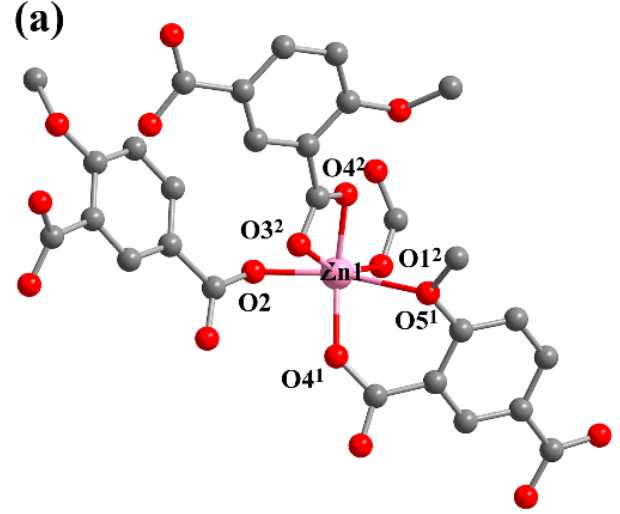

(c)

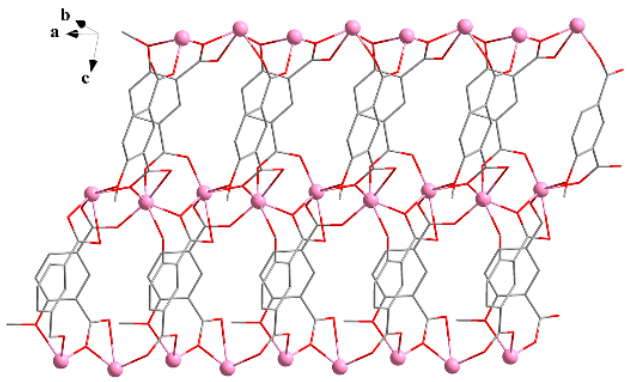

(b)

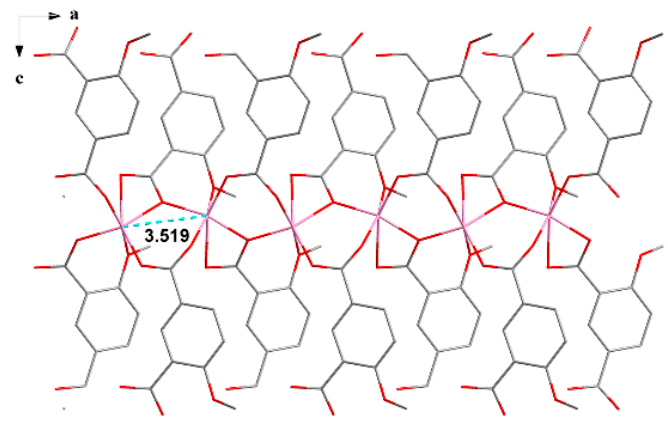

(d)

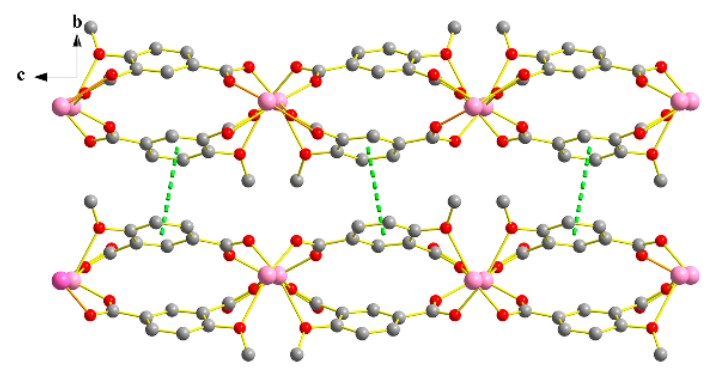

Figure 1. (a) Coordination environment of compound 1, [Zn(MIPA) $]_{n}$. (b) 1D metal chain of $\mathbf{1}$. The $a, b$ and $c$ represent $a$ axis, $b$ axis and $c$ axis, respectively. (c) The 2D layers of 1 . (d) The $\pi \cdots \pi$ interaction between layers. All hydrogen atoms and guest molecules are omitted for clarity. Symmetry codes: (1) $x, 0.5-y,-0.5+z$, (2) $0.5+x, y, 0.5-z$.

\subsection{Crystal Structure of $\left\{\left[\mathrm{Zn}(\mathrm{MIPA})\left(4,4^{\prime}-\text {-bipy }\right)_{0.5}\left(\mathrm{H}_{2} \mathrm{O}\right)\right] \cdot 1.5 \mathrm{H}_{2} \mathrm{O}\right\}_{n}$ (2)}

Single crystal $X$-ray analysis revealed that 2 crystallizes in the monoclinic $C 2 / c$ space group. The asymmetric unit is composed of one $\mathrm{Zn}$ (II) ion, one MIPA, half of a 4,4'-bipy linker, one coordinated water molecule, and one-and-a-half free water molecules. The $\mathrm{Zn} 1$ unit is four-ligated with distorted tetrahedral $\mathrm{ZnO}_{3} \mathrm{~N}$ geometry by two carboxylic O atoms (Zn-O: 1.991(3), 1.948(3) ̊̊) from two MIPA ligands, one coordinated water molecule (Zn-O: 2.055(3) $⿱$ ), and one $\mathrm{N}$ atom $(\mathrm{Zn}-\mathrm{N}: 2.024(4) \AA)$ from a 4,4'-bipy linker (Figure 2). The fully deprotonated MIPA ligands connect the neighboring Zn (II) ions into a 1D W-type chain. As shown in Scheme 1, mode II, all the carboxylic groups of MIPA ligands present a syn-syn- $\mu_{2}-\kappa^{2} \mathrm{O}, \mathrm{O}^{\prime}$ coordination mode. The $1 \mathrm{D}$ chains are arranged in a parallel mode by the 4,4'-bipy linkers, which results in a zigzag 2D hexagone-pattern fold (Figure 3a,b). The terminally-coordinated water molecules that are suspended between the two layers prevent its further extension to a high-dimensional network. Two of the folds are interlocked with each other to give a 2-fold interpenetrating structure (Figure 3c). To better observe the structure, topology analysis was carried out. The Zn(II) ions can be considered as three-connected nodes, while all the MIPA and bpe ligands can be viewed as linkers. Therefore, the structure of compound $\mathbf{2}$ can be simplified as a uninodal three-connected hcb topology with the Schläfli symbol of $6^{3}$ (Figure 3d). 


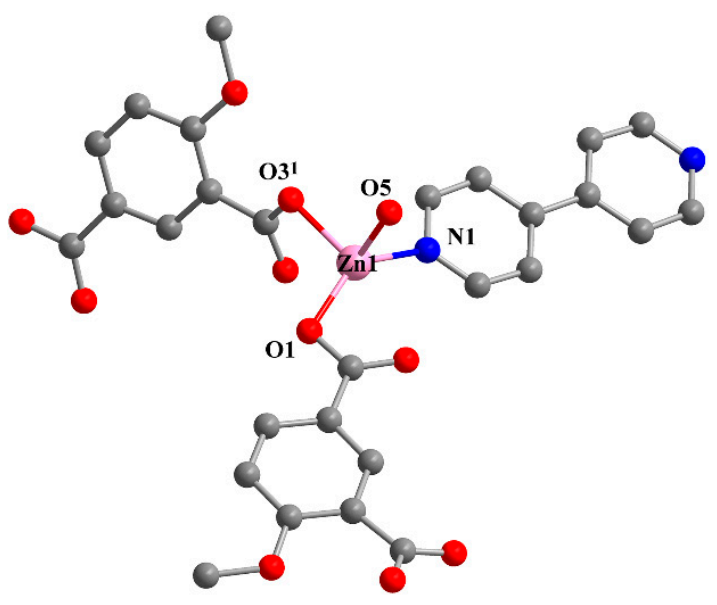

Figure 2. The coordination environment of $\mathrm{Zn} 1$. All hydrogen atoms and guest molecules are omitted for clarity. Symmetry code: (1) $x, 1-y, 0.5+z$.

(a)

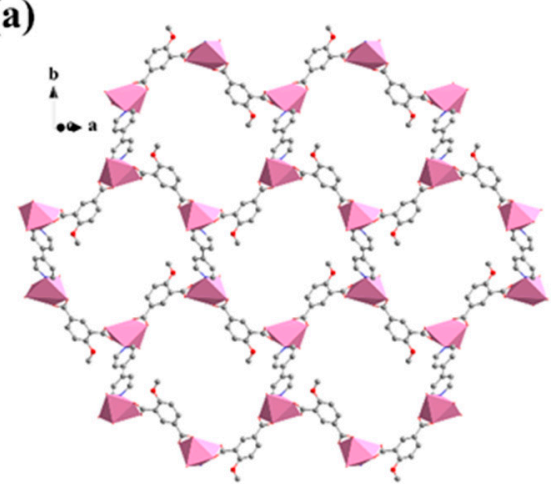

(c)

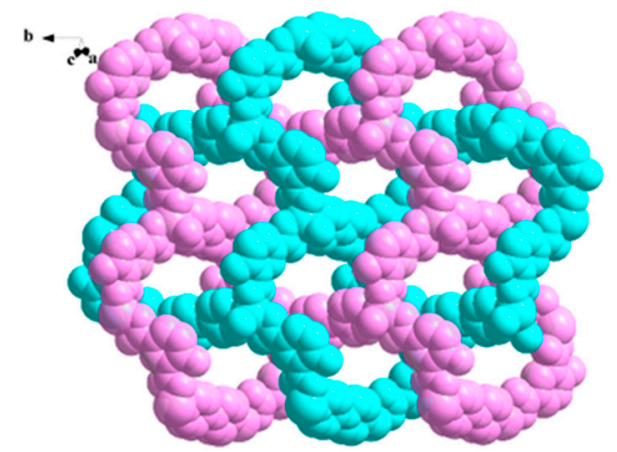

(b)

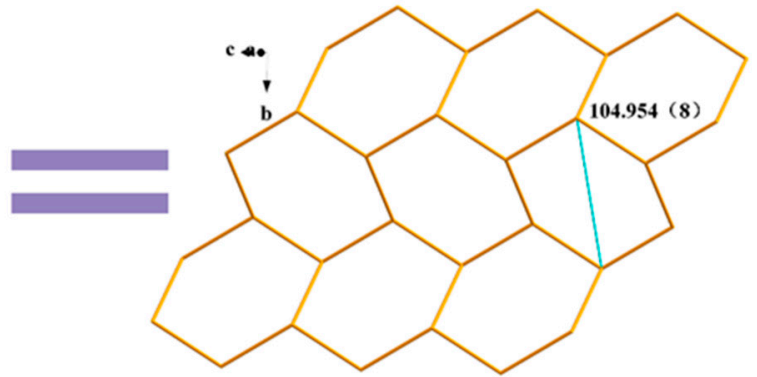

(d)

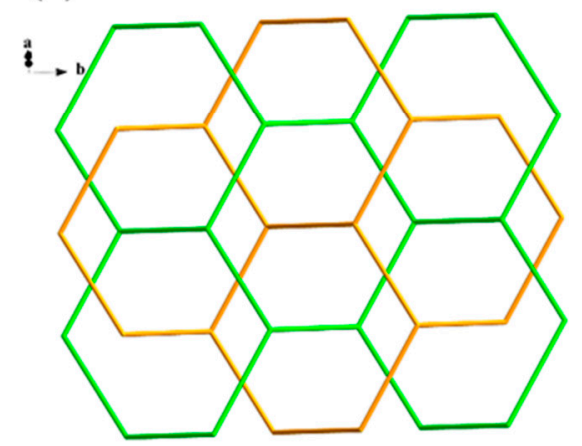

Figure 3. (a) The 2D layer of compound 2, $\left\{\left[\mathrm{Zn}(\mathrm{MIPA})\left(4,4^{\prime}-\text { bipy }\right)_{0.5}\left(\mathrm{H}_{2} \mathrm{O}\right)\right] \cdot 1 \cdot 5 \mathrm{H}_{2} \mathrm{O}\right\}_{\mathrm{n}}$. The a, $\mathrm{b}$ and c represent $a$ axis, $b$ axis and $c$ axis, respectively. (b) The corresponding node-and-linker diagram of the 2D layers in 2. (c) The interpenetrating structure of 2. (d) The corresponding node-and-linker diagram of structures interspersed between 2D layers in 2.

\subsection{Crystal Structure of $\left\{[\mathrm{Zn}(\mathrm{MIPA})(\right.$ bpe $)] \cdot \mathrm{H}_{2} \mathrm{O}_{n}(3)$}

Compound 3 crystallizes in the orthorhombic space group Pnna, presenting a 3-fold interpenetrating 3D structure. An asymmetric unit contains half of a $\mathrm{Zn}(\mathrm{II})$ ion, half of an MIPA ligand, half of a bpe linker, and half of a free water molecule. The $\mathrm{Zn}(\mathrm{II})$ ion exhibits distorted tetrahedral $\mathrm{ZnO}_{2} \mathrm{~N}_{2}$ geometry as it coordinates with two carboxylic O atoms (Zn-O: 1.934(3) $\mathrm{A}$ ) from two different MIPA ligands, and two pyridyl N atoms (Zn-N: 2.059(4) $\AA$ ) from different bpe ligands (Figure 4a). MIPA ligands bind the two adjacent $\mathrm{Zn}$ (II) ions resulting in the formation of a 1D chain (Figure $4 \mathrm{~b}$ ). Here, each carboxylate group adopts a syn-syn- $\mu_{2}-\kappa^{2} \mathrm{O}, \mathrm{O}^{\prime}$ coordination (Scheme 1 , mode II). The $1 \mathrm{D}$ 
helical chain further links with four helices in opposite directions through the four coplanar bpe ligands from the view of the $b$ axis. Consequently, it is extended into a 3D porous framework (Figure 4c). Moreover, three identical frameworks interpenetrate with each other to stabilize the whole structure and almost block the pores. The two-connected bridging of the MIPA ligand and the bpe ligand can be viewed as a linear link. The $\mathrm{Zn}$ (II) ions can be regarded as four-connected nodes. Therefore, the overall structure of 3 is simplified as a uninodal four-connected 3-fold interpenetrating 3D structure with a point symbol of $\left(6^{5} \cdot 8\right)$ (Figure $\left.4 d\right)$.

(a)

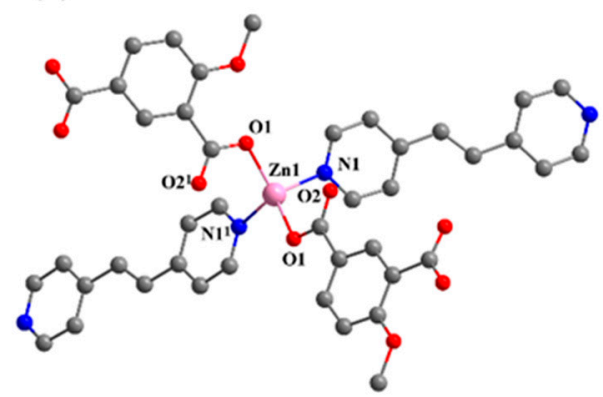

(c)

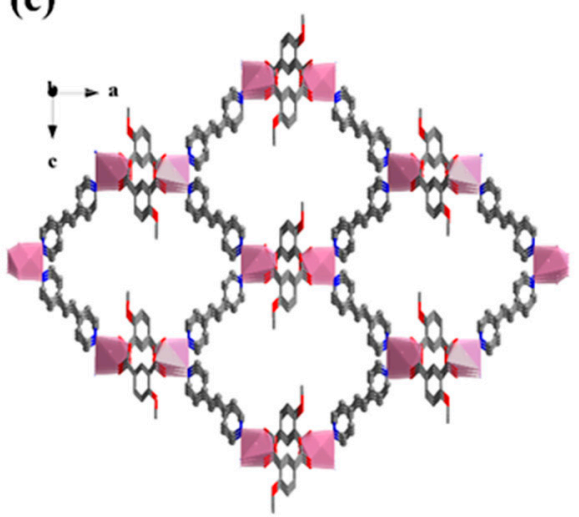

(b)

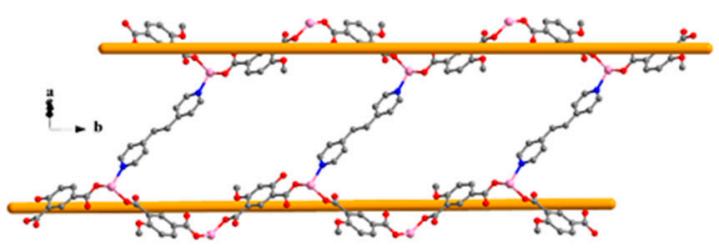

(d)

Figure 4. (a) The coordination environment of Zn1. (b) The left-handed and right-handed chains of compound $3,\left\{[\mathrm{Zn}(\mathrm{MIPA})(\mathrm{bpe})] \cdot \mathrm{H}_{2} \mathrm{O}\right\}_{\mathrm{n}}$. The $\mathrm{a}, \mathrm{b}$ and $\mathrm{c}$ represent $a$ axis, $b$ axis and $c$ axis, respectively. (c) The 3D supramolecular architecture of 3. (d) The four-connected net of 3 . All hydrogen atoms and guest molecules are omitted for clarity. Symmetry code: (1) $x,-y+1 / 2,-z+1 / 2$.

\subsection{Powder Diffraction (PXRD) Analysis and Thermogravimetric Analysis (TGA)}

For compounds 1-3, bulk phase purity was confirmed by the PXRD pattern of the simulated and as-synthesized compounds. The results are shown in Figure S1-it is clearly observable that the bulk phase is in good agreement with the simulated data, confirming all of the compounds are high in purity and can support further study. Thermogravimetric analysis (TGA) of compounds 1-3 was carried out under an $\mathrm{N}_{2}$ atmosphere increasing from 25 to $800{ }^{\circ} \mathrm{C}$ with a flow rate of $10{ }^{\circ} \mathrm{C} \cdot \mathrm{min}^{-1}$. The TG curves are given in Figure 5. For compound 1, no obvious weight loss before $400{ }^{\circ} \mathrm{C}$ was observed, which showed good thermostability. After that, rapid decomposition of the structure occurred. For 2 , a weight loss of $10.4 \%$ was detected in the temperature range of $60-120^{\circ} \mathrm{C}$, which corresponds to the release of both free and coordinated water molecules (calculated, 11.77\%). Subsequently, no significant weight loss was observed until the structure collapsed at $275^{\circ} \mathrm{C}$. Compound 3 was stable until $320^{\circ} \mathrm{C}$, followed by the decomposition of its backbone. 


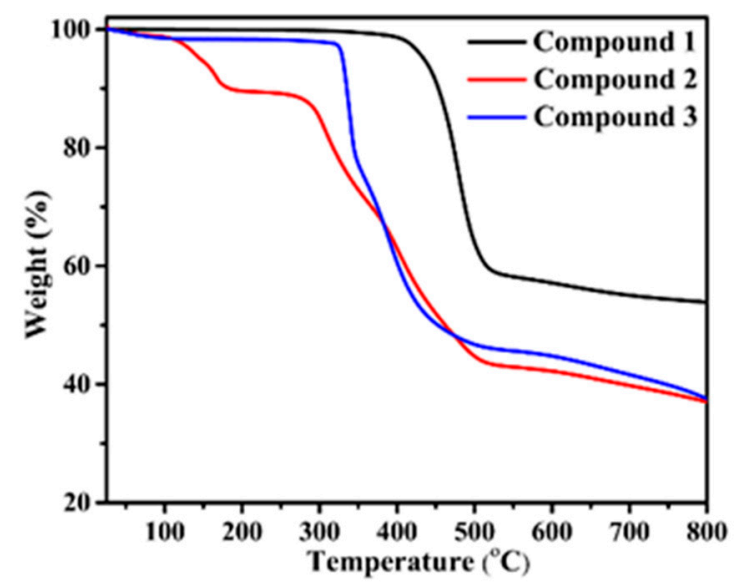

Figure 5. Thermogravimetric curves of the three compounds.

\subsection{Solid-State Luminescence}

The solid-state luminescent emissions of compounds 1, 2, 3, and free ligands were collected at room temperature. The 4,4'-bpy and bpe ligands displayed luminescent emission at $362 \mathrm{~nm}$ and $417 \mathrm{~nm}$, respectively, while the MIPA ligand was not observed to produce luminescent emission (Figures S2 and S3). As illustrated in Figure 6a, upon photoexcitation at $323 \mathrm{~nm}$, weak and broad emission of $\mathbf{1}$ is observed, with a maximum peak of $344 \mathrm{~nm}$ (Figure S4). Compound 2 exhibits stronger emissions at $436 \mathrm{~nm}$, with an excitation peak of $346 \mathrm{~nm}$, while compound 3 is not observed to produce any luminescent emission (Figure S5). The luminescence of $\mathbf{1}$ and $\mathbf{2}$ is due to ligand-based emission, which may be connected with the metal-to-ligand charge transfer, ligand-to-metal charge transfer, or intraligand transitions between ligands [37-40]. The photoluminescent emission of CPs is closely associated with the central metal coordination environment and the property of the ligand. After adding and tuning the $\mathrm{N}$-donor linkers, the coordination environment of metal ions and the structure of the coordination polymers are changed. All of those have effects on the rigidity of the structure and further influence the energy transfer and charge transfer involved in luminescence.

(a)

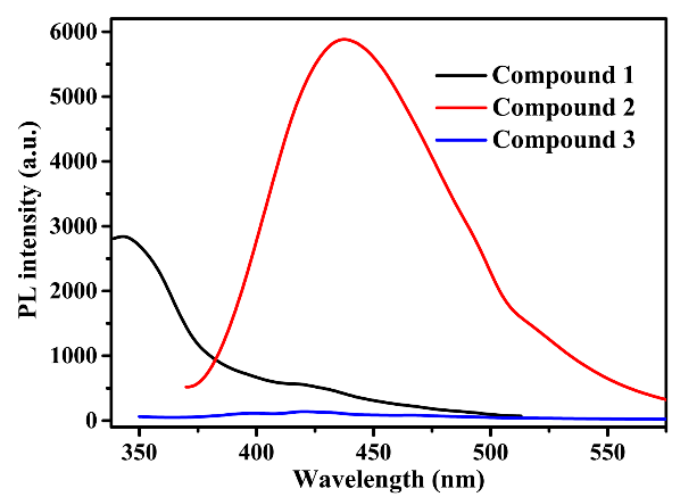

(b)

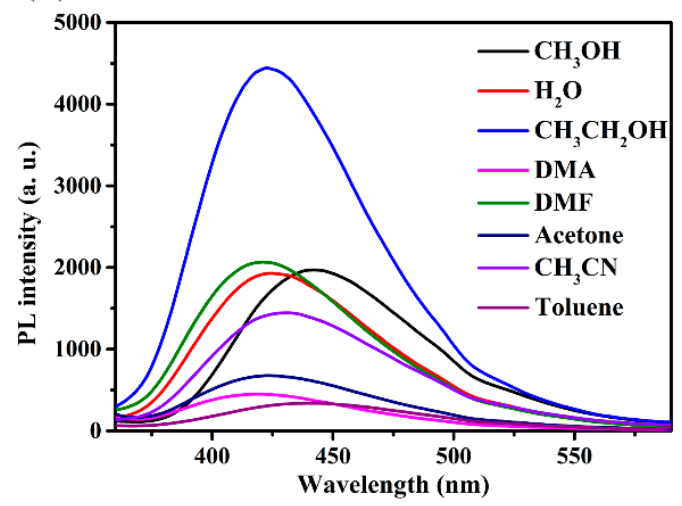

Figure 6. (a) Fluorescence spectra of compounds 1-3 in the solid state. (b) Fluorescence spectra of compound 2 in different solvents.

\subsection{Selectivity toward $A l^{3+}$ Ions}

Compound 2 was selected for use in studying the luminescence responses to various metal cations, owing to its stronger solid-state emission performance. Before the experiment, the fluorescence spectra of compound $\mathbf{2}$ in various solvents were compared and studied (Figure $6 \mathrm{~b}$ ). In view of environmental protection and experimental results, ethanol was used as the main solvent. Compound 2 exhibits stronger emissions at $422 \mathrm{~nm}$ with an excitation peak of $309 \mathrm{~nm}$ in ethanol (Figure 7a). A sample 
of 2 (1 mg) was ground into powder and dispersed in ethanol solution $(4 \mathrm{~mL})$ containing different nitrates (cations: $\mathrm{Mn}^{2+}, \mathrm{Ag}^{+}, \mathrm{Mg}^{2+}, \mathrm{Co}^{2+}, \mathrm{Zn}^{2+}, \mathrm{Cd}^{2+}, \mathrm{Pb}^{2+}, \mathrm{Hg}^{2+}, \mathrm{Al}^{3+}$ ) with a concentration of [M] $=0.4 \mathrm{mM}$. The suspensions were sonicated for $20 \mathrm{~min}$, and then the photoluminescence experiment was conducted. As shown in Figure 7b, with the addition of the different metal cations, most metal cations have different effects on the characteristic peak at $422 \mathrm{~nm}$. Notably, with the addition of $\mathrm{Al}^{3+}$ ions, the luminescence intensity at $422 \mathrm{~nm}$ substantially decreased. The addition of $0.4 \mathrm{mM} \mathrm{Al}^{3+}$ ions can produce a $90 \%$ quenching effect. These results indicate that $\mathbf{2}$ is a powerful sensor for detecting $\mathrm{Al}^{3+}$ ions.

(a)

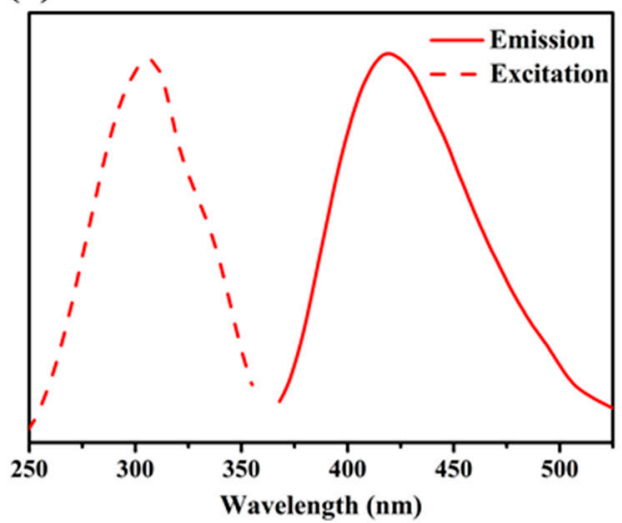

(b)

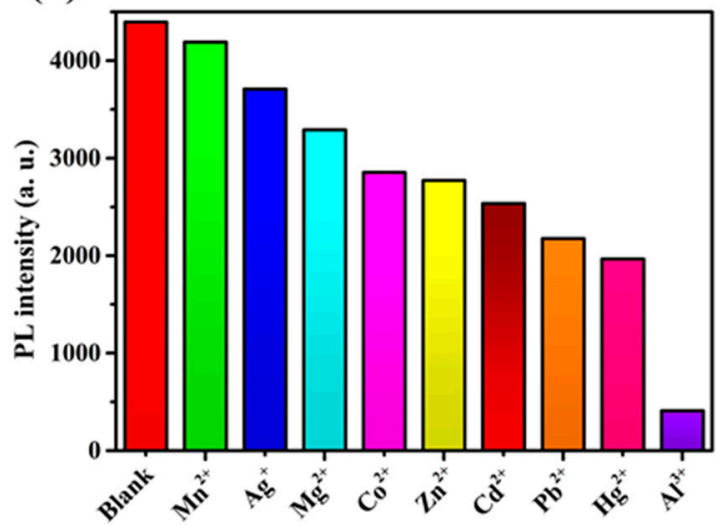

Figure 7. (a) Fluorescence spectra of the ligand in ethanol. (b) Luminescence intensities of 2 in different metal cations.

To better understand the response toward $\mathrm{Al}^{3+}$ ions, the fluorescence spectra upon the additions were collected. As depicted in Figure $8 \mathrm{a}$, with the increasing concentration of $\mathrm{Al}^{3+}$ ions, the emission intensity at $422 \mathrm{~nm}$ gradually decreased and then disappeared for the suspensions. The Stern-Volmer equation can be used to rationalize the quenching effect: $I_{0} / I=1+K_{\mathrm{sv}}[\mathrm{M}]$, where $I_{0}$ and $I$ are the fluorescence intensities before and after adding $\mathrm{Al}^{3+}$ ions, respectively; [M] is the molar concentration(mol/L) of $\mathrm{Al}^{3+}$ ions; and $K_{\mathrm{sv}}$ is the Stern-Volmer constant. As expected, the Stern-Volmer curve for the $\mathrm{Al}^{3+}$ ion is linearly proportional in the range of $0-133 \mathrm{uM}\left(\mathrm{R}^{2}=0.921\right)$, and the value of $K_{\mathrm{sv}}$ is calculated as $9.61 \times 10^{3} \mathrm{M}^{-1}$ (Figure $8 \mathrm{~b}$ ).
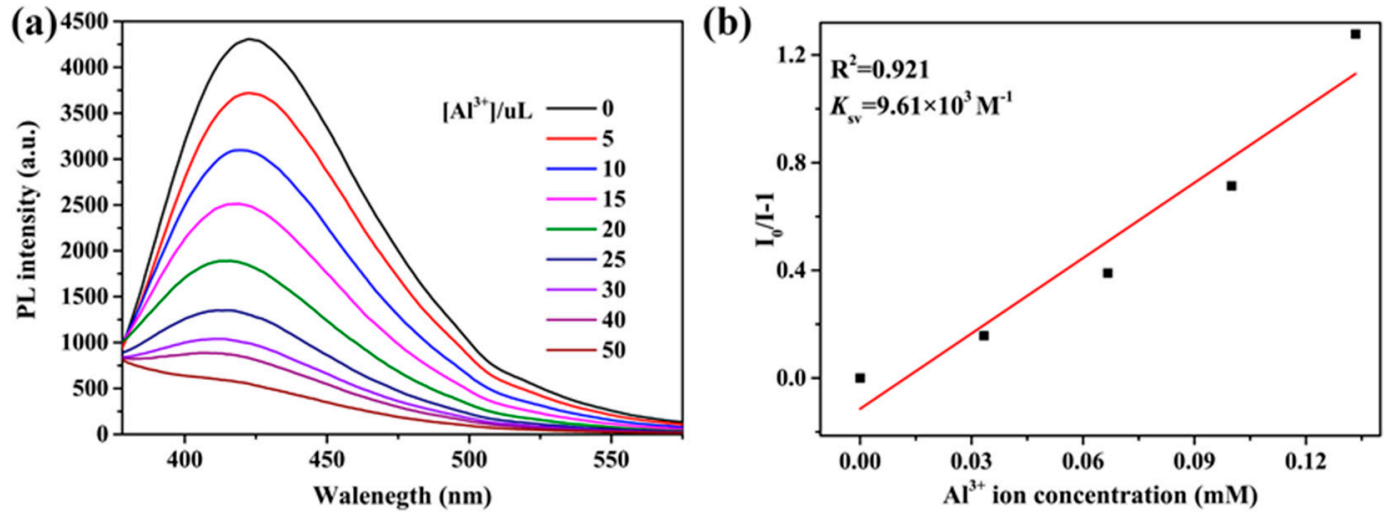

Figure 8. (a) Luminescence intensities of 2 in different concentrations of $\mathrm{Al}^{3+}$ ions. (b) Linear relation between $\mathrm{Al}^{3+}$ ions and $I / I_{0}-1$.

To further study the practicality of compound 2 in the waste solution, different metal cations were introduced into the suspension in the same conditions. As shown in Figure 9, most metal ions had little effect on the detection of $\mathrm{Al}^{3+}$ ions. These experimental results further indicate that compound 2 is a highly selective luminescent sensor for $\mathrm{Al}^{3+}$ ion detection in ethanol. 


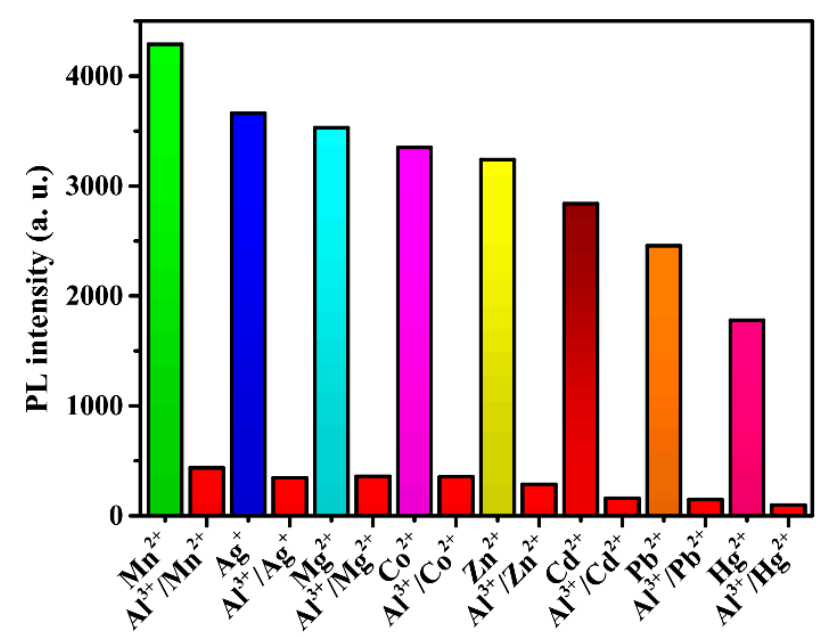

Figure 9. Luminescence intensities of 2 responding to interfering ions in the course of detecting $\mathrm{Al}^{3+}$ ions.

The PXRDs were recorded after the sensing of metal ions. As confirmed by PXRD patterns (Figure S6), the structure of 2 remains unchanged throughout the sensing process, thus eliminating the collapse of the crystal structure. The Uv-vis absorption spectrum was gained at room temperature (Figure S7). There exists a spectrum overlap between the $\mathrm{Uv}$-vis absorption of $\mathrm{Al}^{3+}$ ions and the excitation band of compound 2 , which confirms that there is competitive energy absorption between $\mathrm{Al}^{3+}$ ions and compound 2 . As a result, the phenomenon can be explained either by the competitive energy absorption or the combined action of energy-transfer and competitive energy absorption.

\subsection{Selectivity toward $S^{2-}$ Ions}

Given the sensing ability of anions by compound 2, its ability to sense anions was also examined by the addition of different sodium salts (anions: $\mathrm{I}^{-}, \mathrm{Cl}^{-}, \mathrm{NO}_{3}^{-}, \mathrm{F}^{-}, \mathrm{Br}^{-}, \mathrm{SO}_{4}{ }^{2-}, \mathrm{CH}_{3} \mathrm{COO}^{-}, \mathrm{CO}_{3}{ }^{2-}$, and $\mathrm{S}^{2-}$ ) in ethanol solutions, respectively, into the ethanol suspensions of compound 2 . As shown in Figure 10, different anions have different degrees of influence on the intensity of luminescence, most notably, $\mathrm{S}^{2-}$ ions. When $\mathrm{S}^{2-}$ ions are present in solutions, the luminescence intensity exhibits a significant decline. The concentration of $1.75 \mathrm{mM}$ of $\mathrm{S}^{2-}$ ions can quench the $90 \%$ luminescence intensity. It is clear that $\mathbf{2}$ is an excellent luminescent sensor for the sensitive and selective detection of $\mathrm{S}^{2-}$ ions.

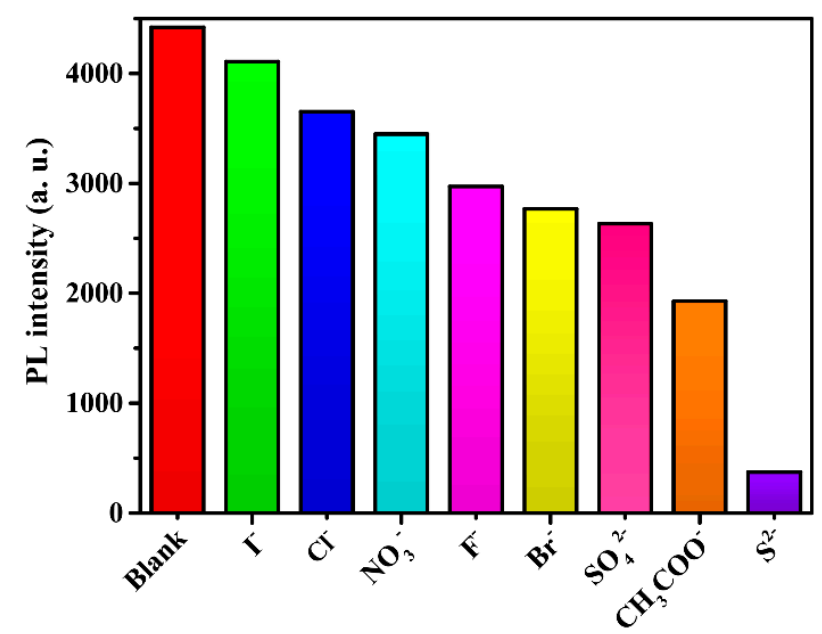

Figure 10. Luminescence intensities of 2 in different anions. 
The sensing sensitivity of 2 toward $S^{2-}$ ions was further examined. As depicted in Figure 11a, the titration curves show that the emission intensity of $\mathbf{2}$ decreased with the addition of increasing concentrations of $S^{2-}$ ions. The luminescence intensity is highly sensitive to $S^{2-}$ ions. The luminescence intensity is observed to be linearly proportional to the concentration of $S^{2-}$ ions in the range of 0-0.333 mM. $\left(\mathrm{R}^{2}=0.969\right)$ (Figure $\left.11 \mathrm{~b}\right)$, indicating the coexistence of dynamic and static quenching processes. The value $K_{\mathrm{sv}}$ is estimated to be $2.14 \times 10^{3} \mathrm{M}^{-1}$.
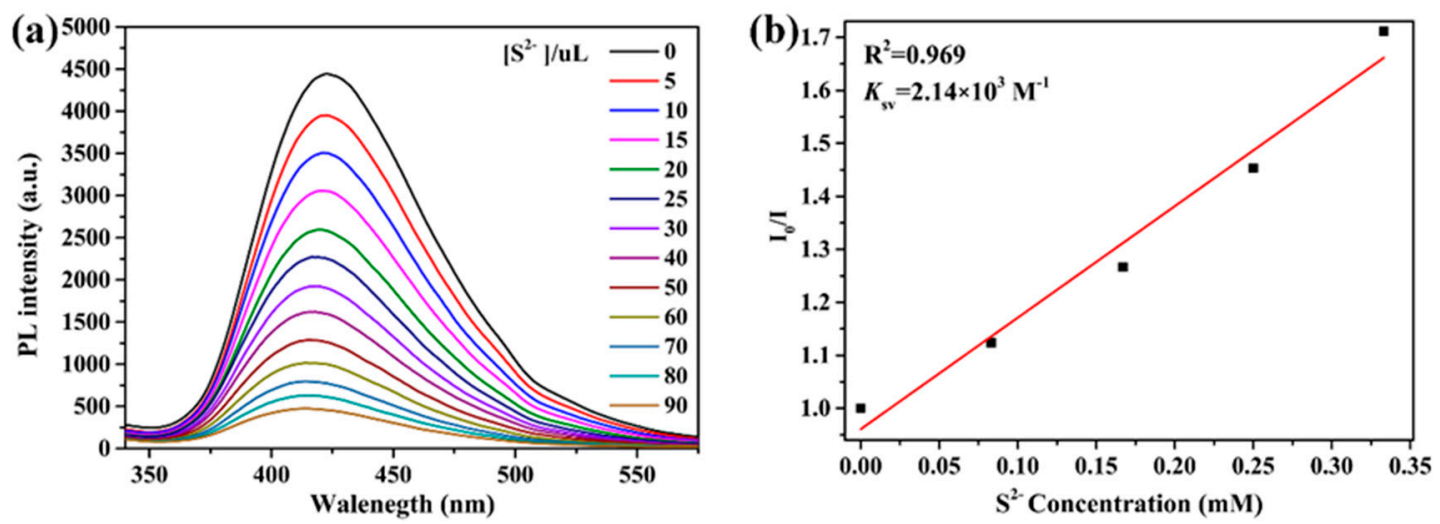

Figure 11. (a) Luminescence intensities of 2 in different concentrations of $\mathrm{S}^{2-}$ ions. (b) Linear relation between $S^{2-}$ ions and $I / I_{0}-1$.

To further check the selective quenching behavior of $S^{2-}$ toward 2, its anti-interference capability was studied. In the same conditions, some other anions were dispersed in suspensions. As shown in Figure 12, most anions had some contribution to luminescence quenching, but the quenching effect grew with the addition of $\mathrm{S}^{2-}$ ions. This further proved that compound $\mathbf{2}$ has remarkable selectivity toward $S^{2-}$ ions in ethanol.

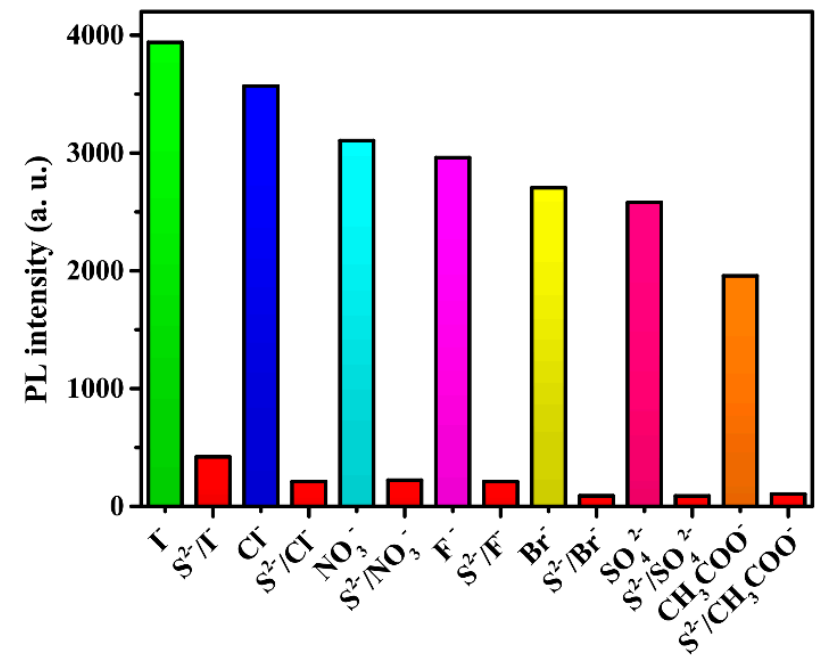

Figure 12. Luminescence intensities of 2 responding to interfering ions in the course of detecting $\mathrm{S}^{2-}$ ions.

The PXRD pattern of compound 2 after sensing $\mathrm{S}^{2-}$ was recorded (Figure S8). The experiment results revealed that the structure of compound 2 remains unchanged throughout the sensing process, demonstrating that the phenomenon is unrelated to the collapse of the frame. The Uv-vis absorption spectrum of $\mathrm{S}^{2-}$ ions and the excitation band of compound 2 have an observable spectral overlap, thus competitive absorption cannot be ruled out (Figure S7). As a result, the phenomenon can be explained both by competitive energy absorption or the combined action of energy-transfer and competitive absorption. 


\section{Experimental}

\subsection{Materials and General Methods}

All reagents and solvents were purchased commercially and used without further purification. Infrared (IR) spectra were obtained through an FTS-400 FT-IR spectrometer together with a KBr pellet from 4000 to $400 \mathrm{~cm}^{-1}$. Powder X-ray diffraction analyses were determined on a Bruker D8 Advance with $\mathrm{Cu} K \alpha$ radiation $(\lambda=1.54 \AA$ ). Elemental analyses of $\mathrm{C}, \mathrm{H}$, and $\mathrm{N}$ were performed in an Elementar Vario EL III analyzer. Thermogravimetric analyses (TGA) were carried out on a Metler-Toledo simultaneous SDT thermal analyzer (Bangkok, Thailand) at a heating rate of $10{ }^{\circ} \mathrm{C} \mathrm{min}^{-1}$ under a $\mathrm{N}_{2}$ atmosphere $\left(\mathrm{N}_{2}\right.$ flow rate $\left.=0.06 \mathrm{~L} \mathrm{~min}^{-1}\right)$. The luminescence spectra were measured on a Lengguang (Shanghai, China) F98 fluorescence spectrophotometer at room temperature.

\subsection{Synthesis of $[\mathrm{Zn}(\mathrm{MIPA})]_{n}(\mathbf{1})$}

MIPA (4.90 mg, $0.0250 \mathrm{mmol})$ and $\mathrm{Zn}\left(\mathrm{NO}_{3}\right)_{2} \cdot 3 \mathrm{H}_{2} \mathrm{O}(29.7 \mathrm{mg}, 0.100 \mathrm{mmol})$ were dissolved in a mixed solvent comprising $\mathrm{DMF} / \mathrm{H}_{2} \mathrm{O} / \mathrm{CH}_{3} \mathrm{OH}(1 / 6 / 8, v / v / v, 2 \mathrm{~mL})$ by sonication, and then sealed in a $5 \mathrm{~mL}$ glass vial and kept at $100{ }^{\circ} \mathrm{C}$ for 2 days. After being cooled to room temperature over $24 \mathrm{~h}$, colorless slice crystals of 1 were obtained (yield 82\% based on MIPA). Elemental analysis calculated (\%) for $\mathrm{C}_{9} \mathrm{H}_{6} \mathrm{O}_{5} \mathrm{Zn}$ : C 41.65, H 2.31. Found: C 42.09, H 2.33. IR (KBr, cm ${ }^{-1}$ ): 3436 (vs), 1629 (s), 1537 (m), $1358(\mathrm{~s}), 1338(\mathrm{~m}), 1001(\mathrm{w}), 791(\mathrm{w}), 636(\mathrm{w})$.

\subsection{Synthesis of $\left\{\left[\mathrm{Zn}(\mathrm{MIPA})\left(4,4^{\prime}-\text { bpy }\right)_{0.5}\left(\mathrm{H}_{2} \mathrm{O}\right)\right] \cdot 1.5 \mathrm{H}_{2} \mathrm{O}\right\}_{n}(2)$}

MIPA (4.90 mg, $0.0250 \mathrm{mmol}), 4,4^{\prime}$-bpy (1.95 mg, $\left.0.0125 \mathrm{mmol}\right)$, and $\mathrm{Zn}\left(\mathrm{NO}_{3}\right)_{2} \cdot 3 \mathrm{H}_{2} \mathrm{O}(29.7 \mathrm{mg}$, $0.100 \mathrm{mmol}$ ) were dissolved in a mixed solvent comprising $\mathrm{DMF} / \mathrm{H}_{2} \mathrm{O}(1 / 2, v / v, 2 \mathrm{~mL})$ by sonication, and then sealed in a $5 \mathrm{~mL}$ glass vial and kept at $100{ }^{\circ} \mathrm{C}$ for 2 days. After being cooled to room temperature over $24 \mathrm{~h}$, colorless block crystals of 2 were obtained (yield 67\% based on MIPA). Elemental analysis calculated (\%) for $\mathrm{C}_{14} \mathrm{H}_{15} \mathrm{ZnNO}_{7.5}$ : C 43.9, H 3.92, N 3.66. Found: C 43.25, H 3.71, N 3.78. IR (KBr, cm${ }^{-1}$ ): 3431 (vs), 1619 (s), 1543 (m), 1381 (s), 1267 (m), 1015 (w), 779 (w), $644(\mathrm{w})$.

\subsection{Synthesis of $\left\{[\mathrm{Zn}(\mathrm{MIPA})(\text { bpe })] \cdot \mathrm{H}_{2} \mathrm{O}\right\}_{n}(3)$}

Compound 3 was obtained by the same procedure used for the preparation of 2 , except that 4,4'-bpy was replaced by bpe $(1.95 \mathrm{mg}, 0.0125 \mathrm{mmol})$. Colorless block crystals of 3 were obtained (yield $74 \%$ based on MIPA). Elemental analysis calculated (\%) for $\mathrm{C}_{21} \mathrm{H}_{17} \mathrm{ZnN}_{2} \mathrm{O}_{6}$ : C 54.9, H 3.70, N 6.10. Found: C 55.05, H 3.66, N 6.36. IR (KBr, cm ${ }^{-1}$ ): 3502 (s), 1605 (vs), 1500 (w), 1383 (m), 1269 (w), 1021 (s), $779(\mathrm{~s}), 680(\mathrm{w}), 551(\mathrm{~m})$.

\subsection{Crystallographic Data Collection and Refinement}

A Bruker Smart APEX II CCD area-detector was utilized to obtain the crystal data of compounds 1-3 at $293 \mathrm{~K}$ using $\omega$ rotation scans with widths of $0.3^{\circ}$ and graphite-monochromated Mo-K $\alpha$ radiation $(\lambda=0.71073 \AA)$. Empirical absorption corrections were applied using the SADABS program. All structures were solved by the direct method and refined by the full-matrix least-squares method on $F^{2}$ with SHELXL-14 software [40-43]. Non-hydrogen atoms were defined by the Fourier synthesis method. Positional and thermal parameters were refined by the full-matrix least-squares method (on $F^{2}$ ) to convergence. Hydrogen atoms of the ligands were initially localized from different Fourier maps and subsequently placed at geometrically ideal positions using riding models with isotropic displacement parameters derived from their carrier atoms. The hydrogen atoms of water were added by the different Fourier maps and refined with suitable constraints. For compound 3, the positioning of the methoxy groups is disordered. The pertinent crystallographic details for compounds $\mathbf{1} \mathbf{- 3}$ are provided in Table 1, while the selected bond lengths and angles are given in Tables S1-S3 in the SI. Crystallographic data are available at the Cambridge Crystallographic Data Center (see in Appendix A). 
Table 1. Crystallographic data and structural parameters of compounds 1-3.

\begin{tabular}{|c|c|c|c|}
\hline Compound & 1 & 2 & 3 \\
\hline Empirical formula & $\mathrm{C}_{9} \mathrm{H}_{6} \mathrm{O}_{5} \mathrm{Zn}$ & $\mathrm{C}_{14} \mathrm{H}_{15} \mathrm{ZnNO}_{7.5}$ & $\mathrm{C}_{21} \mathrm{H}_{17} \mathrm{ZnN}_{2} \mathrm{O}_{6}$ \\
\hline Formula weight & 259.51 & 382.64 & 458.75 \\
\hline Crystal system & Orthorhombic & Monoclinic & Orthorhombic \\
\hline Space group & Pbca & $C 2 / c$ & Pnna \\
\hline$a / \AA$ & $6.9761(17)$ & $18.346(3)$ & $7.996(2)$ \\
\hline$b / \AA$ & $14.443(4)$ & $12.2149(16)$ & $17.355(5)$ \\
\hline$c / \AA$ & $17.319(4)$ & $16.850(3)$ & $15.110(4)$ \\
\hline$\alpha /^{\circ}$ & 90.00 & 90.00 & 90.00 \\
\hline$\beta /^{\circ}$ & 90.00 & $121.911(2)$ & 90.00 \\
\hline$\gamma /{ }^{\circ}$ & 90.00 & 90.00 & 90.00 \\
\hline Volume $/ \AA^{3}$ & $1745.0(8)$ & 3205.26 & $2096.8(10)$ \\
\hline Z & 8 & 8 & 8 \\
\hline$D_{c} / \mathrm{g} \mathrm{cm}^{-3}$ & 1.976 & 1.586 & 1.453 \\
\hline$\mu / \mathrm{mm}^{-1}$ & 2.810 & 1.571 & 1.211 \\
\hline$F(000)$ & 1040.0 & 1568.0 & 940.0 \\
\hline Independent reflections & 2090 & 3772 & 2543 \\
\hline$R_{\text {int }}$ & 0.1138 & 0.0405 & 0.0494 \\
\hline Goodness-of-fit on $F^{2}$ & 0.954 & 1.024 & 1.036 \\
\hline$R^{1}, w R^{2}(\mathrm{I}>=2 \sigma(I))$ & $0.0508,0.1046$ & $0.0450,0.1255$ & $0.0553,0.1621$ \\
\hline$R^{1}, w R^{2}$ (all data) & $0.1393,0.1339$ & $0.0776,0.1421$ & $0.1039,0.1863$ \\
\hline$\Delta \rho_{\max } / \Delta \rho_{\min }\left(\mathrm{e} \AA^{-3}\right)$ & $1.43 /-0.74$ & $0.5 /-0.65$ & $0.42 /-0.5$ \\
\hline
\end{tabular}

\section{Conclusions}

In conclusion, three coordination polymers, $[\mathrm{Zn}(\mathrm{MIPA})]_{\mathrm{n}} \quad(\mathbf{1}), \quad\left\{\left[\mathrm{Zn}(\mathrm{MIPA})\left(4,4^{\prime}-\right.\right.\right.$ bpy) $\left.\left.\left(\mathrm{H}_{2} \mathrm{O}\right)_{0.5}\right] \cdot \mathrm{H}_{2} \mathrm{O}\right\}_{\mathrm{n}}(2)$, and $\left\{[\mathrm{Zn}(\mathrm{MIPA})(\mathrm{bpe})] \cdot \mathrm{H}_{2} \mathrm{O}\right\}_{\mathrm{n}}(3)$ (MIPA = 4-methoxyisophthalic acid, bpe = (E)-1,2-di(pyridine-4-yl)ethene), have been successfully synthesized by adding auxiliary ligands and controlling solvent effects. All the structures of compounds 1-3 were characterized by infrared, PXRD, and TGA studies. The fluorescence properties of compounds 1-3 were explored, and it was found that $\mathbf{2}$ has strong fluorescence emission. Fluorescence titration of compound $\mathbf{2}$ exhibits a selective and highly sensitive quenching efficiency toward $\mathrm{Al}^{3+}$ and $\mathrm{S}^{2-}$ ions in ethanol, even in the presence of disturbing ions. Either the presence of competitive energy absorption or the combined action of energy-transfer and competitive energy absorption is the main reason for the detection of the $\mathrm{Al}^{3+}$ and $\mathrm{S}^{2-}$ ions in ethanol. Moreover, this work is meaningful since it proves the potential for detecting $\mathrm{Al}^{3+}$ and $\mathrm{S}^{2-}$ ions based on coordination polymers.

Supplementary Materials: The following are available online. Figure S1: Powder diffraction (PXRD) of three compounds, Figure S2: Powder X-ray patterns of $\mathrm{Al}^{3+} @$ compound 2 and as-synthesized 2, Figure S3: The ultraviolet spectra of compound 2, $\mathrm{S}^{2-}$ and $\mathrm{Al}^{3+}$ in ethanol solutions, Figure S4: Powder X-ray patterns of $\mathrm{S}^{2-} @$ compound 2 and as-synthesized 2, Figure S5: Infrared spectra of compounds, Table S1: Selected bond lengths $(\AA)$ and angles $\left({ }^{\circ}\right)$ of compound 1, Table S2: Selected bond lengths $(\AA)$ and angles $\left(^{\circ}\right)$ of compound 2, Table S3: Selected bond lengths $(\AA)$ and angles $\left(^{\circ}\right)$ of compound 3 .

Author Contributions: Conceptualization: X.Z. and Y.Z.; methodology, X.Z.; software, S.L.; validation, X.Z., S.Z., and X.Z.; formal analysis, Y.W.; investigation, Q.Z.; resources, L.J.; data curation, Y.W.; writing-original draft preparation, L.D.; writing - review and editing, Y.W. Please refer to the CRediT taxonomy for the term explanations. All authors have read and agreed to the published version of the manuscript.

Funding: This work was supported by the National Natural Science Foundation of China (Project 21561033).

Conflicts of Interest: The authors declare no conflict of interest. 


\section{Appendix A}

CCDC 1863388 (1), 1863389 (2), and 1863390 (3) contain the supplementary crystallographic data for the present paper. These data can be obtained free of charge from the Cambridge Crystallographic Data Center via the internet at http://www.ccdc.cam.ac.uk/data_request/cif, or by e-mailing data_request@ccdc.cam.ac.uk.

\section{References}

1. So, H.; Chae, J.B.; Kim, C. A thiol-containing colorimetric chemosensor for relay recognition of $\mathrm{Cu}^{2+}$ and $\mathrm{S}^{2-}$ in aqueous media with a low detection limit. Inorg. Chim. Acta 2019, 492, 83-90. [CrossRef]

2. Zhan, Z.; Jia, Y.; Li, D.; Zhang, X.; Hu, M. A water-stable terbium-MOF sensor for the selective, sensitive, and recyclable detection of $\mathrm{Al}^{3+}$ and $\mathrm{CO}_{3}{ }^{2-}$ ions. Dalton Trans. 2019, 48, 15255-15262. [CrossRef] [PubMed]

3. Wang, X.R.; Huang, Z.; Du, J.; Wang, X.Z.; Gu, N.; Tian, X.; Li, Y.; Liu, Y.Y.; Huo, J.Z.; Ding, B. Hydrothermal preparation of five rare-earth $(\mathrm{Re}=\mathrm{Dy}, \mathrm{Gd}, \mathrm{Ho}, \mathrm{Pr}$, and $\mathrm{Sm})$ luminescent cluster-based coordination materials: The first MOFs-based ratiometric fluorescent sensor for lysine and bifunctional sensing platform for lnsulin and $\mathrm{Al}^{3+}$. Inorg. Chem. 2018, 57, 12885-12899. [CrossRef] [PubMed]

4. Joo, D.H.; Mok, J.S.; Bae, G.H.; Oh, S.E.; Kang, J.H.; Kim, C. Colorimetric detection of $\mathrm{Cu}^{2+}$ and fluorescent detection of $\mathrm{PO}_{4}{ }^{3-}$ and $\mathrm{S}^{2-}$ by a multifunctional chemosensor. Ind. Eng. Chem. Res. 2017, 56, 8399-8407. [CrossRef]

5. Chen, X.; Peng, Y.; Han, X.; Liu, Y.; Lin, X.; Cui, Y. Sixteen isostructural phosphonate metal-organic frameworks with controlled Lewis acidity and chemical stability for asymmetric catalysis. Nat. Commun. 2017, 8, 2171. [CrossRef]

6. Zhao, N.; Li, Y.; Gu, J.Z.; Fernandes, T.A.; Kirillova, M.V.; Kirillov, M.A. New copper (II) coordination compounds assembled from multifunctional pyridine carboxylate blocks: Synthesis, structures, and satalytic activity in cycloalkane oxidation. Molecules 2019, 24, 6. [CrossRef]

7. Ji, P.; Drake, T.; Murakami, A.; Oliveres, P.; Skone, J.H.; Lin, W. Tuning Lewis acidity of metal-organic frameworks via perfluorination of bridging ligands: Spectroscopic, theoretical, and catalytic studies. J. Am. Chem. Soc. 2018, 140, 10553-10561. [CrossRef]

8. Zhu, J.; Usov, P.M.; Xu, W.; Celis-Salazar, P.J.; Lin, S.; Kessinger, M.C.; Landaverde-Alvarado, C.; Cai, M.; May, A.M.; Slebodnick, C.; et al. A new class of metal-cyclam-based zirconium metal-organic frameworks for $\mathrm{CO}_{2}$ adsorption and chemical fixation. J. Am. Chem. Soc. 2018, 140, 993-1003. [CrossRef]

9. Erhart, O.; Georgiev, P.A.; Krautscheid, H. Desolvation process in the flexible metal-organic framework [Cu (Me-4py-trz-ia)], adsorption of dihydrogen and related structure responses. CrystEngComm 2019, 21, 6523-6535. [CrossRef]

10. Zhang, Y.; Wang, L.; Zeng, M.; Kurmoo, M. Fabrication of a capillary column coated with the four-fold-interpenetrated MOF Cd (D-Cam) (tmdpy) for gas chromatographic separation. Inorg. Chem. Commun. 2017, 83, 123-126. [CrossRef]

11. Wang, Q.; Luo, Y.; Hou, R.; Zaman, S.; Qi, K.; Liu, H.; Park, H.S.; Xia, B.Y. Redox tuning in crystalline and electronic structure of bimetal-organic frameworks derived cobalt/nickel boride/sulfide for boosted faradaic capacitance. Adv. Mater. 2019, 31, e1905744. [CrossRef] [PubMed]

12. Yuan, Z.; Yin, Y.; Xie, C.; Zhang, H.; Yao, Y.; Li, X. Advanced materials for zinc-based flow battery: Development and challenge. Adv. Mater. 2019, 31, e1902025. [CrossRef] [PubMed]

13. Dolgopolova, E.A.; Brandt, A.J.; Ejegbavwo, O.A.; Duke, A.S.; Maddumapatabandi, T.D.; Galhenage, R.P.; Larson, B.W.; Reid, O.G.; Ammal, S.C.; Heyden, A.; et al. Electronic properties of bimetallic metal-organic frameworks (MOFs): Tailoring the density of electronic states through MOF modularity. J. Am. Chem. Soc. 2017, 139, 5201-5209. [CrossRef] [PubMed]

14. Liu, Y.; Xie, X.Y.; Cheng, C.; Shao, Z.S.; Wang, H.S. Strategies to fabricate metal-organic framework (MOF)-based luminescent sensing platforms. J. Mater. Chem. C 2019, 7, 10743-10763. [CrossRef]

15. Ma, Y.L.; Tang, H.J.; Dong, X.; Wang, K.M.; Liu, M.H.; Wang, Y.N. A dual-functional 3D coordination polymer as a luminescent sensor for acetone in an aqueous medium and detecting the temperature. Inorg. Chem. Commun. 2019, 105, 13-19. [CrossRef] 
16. Rosario, J.; da Luz, L.L.; Geris, R.; Ramalho, J.G.S.; da Silva, A.F.; Junior, S.A.; Malta, M. Photoluminescent organisms: How to make fungi glow through biointegration with lanthanide metal-organic frameworks. Nat. Communt. 2019, 9, 7302. [CrossRef]

17. Wang, K.M.; Ma, Y.L.; Tang, H.J. Lanthanide Coordination Polymers as Luminescent Sensors for the Selective and Recyclable Detection of Acetone. Crystals 2017, 7, 199. [CrossRef]

18. Hou, B.L.; Tian, D.; Liu, J.; Dong, L.Z.; Li, S.L.; Li, D.S.; Lan, Y.Q. A water-stable metal-organic framework for highly sensitive and selective sensing of $\mathrm{Fe}^{3+}$ ion. Inorg. Chem. 2016, 55, 10580-10586. [CrossRef]

19. Guo, L.; Liu, Y.; Kong, R.; Chen, G.; Liu, Z.; Qu, F.; Xia, L.; Tan, W. A metal-organic framework as selectivity regulator for $\mathrm{Fe}^{3+}$ and ascorbic acid detection. Anal. Chem. 2019, 91, 12453-12460. [CrossRef]

20. Zhou, A.M.; Wei, H.; Liu, J.P.; Zhang, X.M.; Shi, D.; Zhu, C.; Schipper, D.; Jones, R.A. Two 2D multiresponsive luminescence coordination polymers for selective sensing of $\mathrm{Fe}^{3+}, \mathrm{Cr}^{\mathrm{VI}}$ anions and TNP in aqueous medium. CrystEngComm 2019, 21, 5185-5194. [CrossRef]

21. Li, H.; Han, W.; Lv, R.; Zhai, A.; Li, X.L.; Gu, W.; Liu, X. Dual-function mixed-lanthanide metal-organic framework for ratiometric water detection in bioethanol and temperature sensing. Anal. Chem. 2019, 91, 2148-2154. [CrossRef] [PubMed]

22. Kang, X.-M.; Fan, X.-Y.; Hao, P.-Y.; Wang, W.-M.; Zhao, B. A stable zinc-organic framework with luminescence detection of acetylacetone in aqueous solution. Inorg. Chem. Front. 2019, 6, 271-277. [CrossRef]

23. Vasylevskyi, S.I.; Bassani, D.M.; Fromm, K.M. Anion-induced structural diversity of Zn and Cd coordination polymers based on bis-9,10-(pyridine-4-yl)-anthracene, their luminescent properties, and highly efficient sensing of nitro derivatives and herbicides. Inorg. Chem. 2019, 58, 5646-5653. [CrossRef] [PubMed]

24. Huang, W.H.; Ren, J.; Yang, Y.H.; Li, X.M.; Wang, Q.; Jiang, N.; Yu, J.Q.; Wang, F.; Zhang, J. Water-stable metal-organic frameworks with selective sensing on $\mathrm{Fe}^{3+}$ and nitroaromatic explosives, and stimuli-responsive luminescence on lanthanide encapsulation. Inorg. Chem. 2019, 58, 1481-1491. [CrossRef]

25. Li, L.; Cheng, J.; Liu, Z.; Song, L.; You, Y.; Zhou, X.; Huang, W. Ratiometric luminescent sensor of picric acid based on the dual-emission mixed-lanthanide coordination polymer. ACS Appl. Mater. Interfaces 2018, 10, 44109-44115. [CrossRef]

26. Tian, D.; Liu, X.J.; Feng, R.; Xu, J.L.; Xu, J.; Chen, R.Y.; Huang, L.; Bu, X.H. Microporous luminescent metal-organic framework for a sensitive and selective fluorescence sensing of toxic mycotoxin in moldy sugarcane. ACS Appl. Mater. Interfaces 2018, 10, 5618-5625. [CrossRef] [PubMed]

27. Han, Z.; Wang, K.; Guo, Y.; Chen, W.; Zhang, J.; Zhang, X.; Siligardi, G.; Yang, S.; Zhou, Z.; Sun, P.; et al. Cation-induced chirality in a bifunctional metal-organic framework for quantitative enantioselective recognition. Nat. Commun. 2019, 10, 5117. [CrossRef] [PubMed]

28. Wang, J.; Wu, J.; Lu, L.; Ma, A.Q.; Hu, W.S.; Wu, W.P.; Wu, Y.; Sun, Y.C.; Singh, A.; Kumar, A. Two chemically stable Cd (II) polymers as fluorescent sensor and photocatalyst for aromatic dyes. Polymers 2018, 10, 274. [CrossRef] [PubMed]

29. Ghorai, P.; Dey, A.; Hazra, A.; Dutta, B.; Brandão, P.; Ray, P.P.; Banerjee, P.; Saha, A. Cd (II) based coordination polymer series: Fascinating structures, efficient semiconductors, and promising nitro aromatic sensing. Cryst. Growth Des. 2019, 19, 6431-6447. [CrossRef]

30. Tunsrichon, S.; Boonmak, J.; Youngme, S. Ultrasonic-assisted synthesis of a Zn (II) coordination polymer in aqueous media and its high-performance luminescent sensing for 2,4,6-trinitrophenol. Cryst. Growth Des. 2019, 19, 2139-2148. [CrossRef]

31. Wang, C.C.; Ke, S.Y.; Cheng, C.W.; Wang, Y.W.; Chiu, H.S.; Ko, Y.C.; Sun, N.K.; Ho, M.L.; Chang, C.K.; Chuang, Y.C.; et al. Four mixed-ligand Zn (II) three-dimensional metal-organic frameworks: Synthesis, structural diversity, and photoluminescent property. Polymers 2017, 9, 644. [CrossRef] [PubMed]

32. He, H.M.; Zhu, Q.Q.; Li, C.P.; Du, M. Design of a highly-stable pillar-layer Zinc (II) porous framework for rapid, reversible, and multi-responsive luminescent sensor in water. Cryst. Growth Des. 2019, 19, 2139-2148. [CrossRef]

33. Zhang, W.H.; Dong, Z.; Wang, Y.Y.; Hou, L.; Jin, J.C.; Huang, W.H.; Shi, Q.Z. Synthesis, structural diversity and fluorescent characterisation of a series of $\mathrm{d}^{10}$ metal-organic frameworks (MOFs): Reaction conditions, secondary ligand and metal effects. Dalton Trans. 2011, 40, 2509-2521. [CrossRef] [PubMed]

34. Rogovoy, M.I.; Berezin, A.S.; Kozlova, Y.N.; Samsonenko, D.G.; Artem'ev, A.V. A layered Ag (I)-based coordination polymer showing sky-blue luminescence and antibacterial activity. Inorg. Chem. Commun. 2019, 108, 107513. [CrossRef] 
35. Chen, D.M.; Tian, J.Y.; Chen, M.; Liu, C.S.; Du, M. Moisture-stable Zn (II) metal-organic framework as a multifunctional platform for highly efficient $\mathrm{CO}_{2}$ capture and nitro pollutant vapor detection. ACS Appl. Mater. Interfaces 2016, 8, 18043-18050. [CrossRef]

36. Liang, X.; Guo, Z.; Wei, H.; Liu, X.; Lv, H.; Xing, H. Selective photooxidation of sulfides mediated by singlet oxygen using visible-light-responsive coordination polymers. Chem. Commun. 2018, 54, 13002-13005. [CrossRef]

37. Artem'ev, A.V.; Doronina, E.P.; Rakhmanova, M.L.; Tarasova, O.A.; Bagryanskaya, L.Y.; Nedolya, N.A. Chemoselective mechanochemical route toward a bright TADF-emitting CuI-based coordination polymer. Inorg. Chem. Front. 2019, 6, 671. [CrossRef]

38. Berezin, A.S.; Davydova, M.P.; Bagryanskaya, L.Y.; Artyushin, O.I.; Brel, V.K.; Artem'ev, A.V. A red-emitting Mn (II)-based coordination polymer build on 1,2,4,5-tetrakis (diphenylphosphinyl) benzene. Inorg. Chem. Commun. 2019, 107, 107473. [CrossRef]

39. Qi, Y.J.; Wang, Y.J.; Li, X.X.; Zhao, D.; Sun, Y.Q.; Zheng, S.T. Two $\mathrm{d}^{10}$ metal-organic frameworks as low-temperature luminescent molecular thermometers. Cryst. Growth Des. 2018, 18, 7383-7390. [CrossRef]

40. Sheldrick, G.M. Program for the Refinement of Crystal Structures; University of Göttingen: Göttingen, Germany, 1993.

41. Sheldrick, G.M. A short history of SHELX. Acta Crystallogr. Sect. A 2008, 64, 112-122. [CrossRef]

42. Sheldrick, G.M. Crystal structure refinement with SHELXL. Acta Crystallogr. Sect. C 2015, 71, 3-8. [CrossRef] [PubMed]

43. Burla, M.C.; Caliandro, R.; Camalli, M.; Carrozzini, B.; Cascarano, G.L.; De Caro, L.; Giacovazzo, C.; Polidori, G.; Spagna, R. SIR2004: An improved tool for crystal structure determination and refinement. J. Appl. Cryst. 2005, 38, 381-388. [CrossRef]

Sample Availability: Samples of the compounds 1-3 are available from the authors.

(C) 2020 by the authors. Licensee MDPI, Basel, Switzerland. This article is an open access article distributed under the terms and conditions of the Creative Commons Attribution (CC BY) license (http://creativecommons.org/licenses/by/4.0/). 